\title{
Composição lipídica, características físicas e sensoriais de recheios de morango em biscoitos
}

\author{
Lipid composition and the physical and sensory characteristics of strawberry \\ biscuit fillings
}

\author{
Eliane Harumi Akamine', Izabela Dutra Alvim', Ana Maria Rauen Oliveira Miguel ${ }^{2}$, \\ Kátia Maria Vieira Avelar Bittencourt Cipolli ${ }^{2}$, Carla Lea de Camargo Vianna Cruz ${ }^{1 *}$ \\ ${ }^{1}$ Instituto de Tecnologia de Alimentos (ITAL), Centro de Tecnologia de Cereais e Chocolate, Campinas/SP - Brasil \\ 2Instituto de Tecnologia de Alimentos (ITAL), Centro de Ciência e Qualidade de Alimentos, Campinas/SP - Brasil

\section{${ }^{*}$ Corresponding Author} \\ Carla Lea de Camargo Vianna Cruz, Instituto de Tecnologia de Alimentos (ITAL), Centro de Tecnologia de Cereais e Chocolate, Avenida Brasil, 2880, \\ CEP: 13070-178, Campinas/SP - Brasil, e-mail: carla.lea@ital.sp.gov.br
}

Cite as: Lipid composition and the physical and sensory characteristics of strawberry biscuit fillings. Braz. J. Food Technol., v. 21, e2016120, 2018.

Received: Sept. 17, 2016; Accepted: Apr. 19, 2017

\section{Resumo}

Recheios de biscoito de cinco marcas comerciais brasileiras foram avaliados quanto a teor de lipídios, composição em ácidos graxos, atividade de água, diâmetro médio e distribuição do tamanho de partícula, aspecto morfológico, textura (firmeza e adesividade), além de avaliação sensorial, por teste de aceitação, quanto aos atributos: sabor global, sabor de morango, cor, arenosidade, cerosidade e firmeza. Os cinco recheios comerciais avaliados apresentam valores de atividade de água de 0,47 a 0,50. Apenas um diferiu quanto ao tamanho de partícula, apresentando o maior diâmetro médio e a menor aceitação da arenosidade. Quanto à firmeza, houve maior variação entre as marcas comerciais (37,41 a 124,04 gf), assim como na composição em ácidos graxos, indicando diferentes fontes lipídicas nas gorduras destinadas aos recheios. O teor médio de lipídios encontrado, 27,5\%, está próximo ao da literatura, de 30\%; porém, de acordo com a composição em ácidos graxos, o valor médio de ácidos graxos trans encontrado indica que a indústria pode estar realmente reduzindo os teores desses ácidos graxos, não obstante os valores de ácidos graxos saturados ainda mostrarem-se altos.

Palavras-chave: Biscoitos recheados; Ácidos graxos; Parâmetros físicos; Diâmetro médio de partícula; Aceitação.

\section{Abstract}

The fillings of five Brazilian brands of sandwich cookies were evaluated for their lipid content, fatty acid composition, water activity, average diameter and particle size distribution, morphological appearance, texture (firmness and adhesiveness) and sensory acceptance for the attributes of: overall flavour, strawberry flavour, colour, grittiness, waxiness and firmness. The five commercial fillings showed values for water activity of from 0.47 to 0.50 . Only one sample differed in particle size, presenting a larger mean diameter and lower acceptance due to grittiness. There was greater variation in firmness between the commercial brands (from 37.41 to $124.04 \mathrm{gf}$ ) as well as in the fatty acid composition, indicating that the fats used in the fillings came from different lipid sources. The average lipid content was $27.5 \%$, which was close to the value found in the literature of $30 \%$. With respect to the fatty acid composition, the average value for trans fatty acids indicated that the industries were really reducing the levels of these fatty acids, but the amounts of saturated fatty acids were still high.

Keywords: Sandwich cookies; Fatty acids; Physical parameters; Average particle diameter; Acceptance. 


\section{Introdução}

O Brasil é o segundo maior mercado de biscoitos em vendas, com um consumo per capita de $8,4 \mathrm{~kg} / \mathrm{ano}$, e registra-se presença do produto em $99,6 \%$ dos lares brasileiros, segundo dados da Associação Brasileira das Indústrias de Biscoitos, Massas Alimentícias e Pães \& Bolos Industrializados. O segmento que mais vende é o de recheados, com estimativa de que cerca de 450 mil toneladas de biscoitos recheados foram comercializadas em 2014 (ABIMAPI, 2015).

As principais características que influenciam a preferência do consumidor por um determinado recheio de biscoito são sua baixa arenosidade e boa dissolução na boca (ORMENESE et al., 2001). Essas características são determinadas por seus principais ingredientes, a gordura e o açúcar, correspondendo estes, em média, a 94\% de sua composição (GOMES et al., 2010).

Em recheios de biscoito, há a necessidade de uma sensação suave e rápida da dissolução do açúcar na boca (MANLEY, 1998). Assim, a sacarose deve estar na forma de pó, com pouco ou nenhum cristal de grande dimensão, pois quanto menor a partícula de açúcar, mais rapidamente ela se dissolverá na boca. Existe um limite, próximo a $30 \mu \mathrm{m}$, abaixo do qual as partículas individuais não são percebidas na boca e, acima desse limite, o recheio é percebido como granuloso e/ou arenoso (LINDEN; LORIENT, 1996).

A dissolução do recheio também é influenciada pela gordura, ou seja, a gordura tem papel fundamental nas características de textura do recheio, na sua consistência e, consequentemente, na sua dissolução (STAUFFER, 2006). As propriedades físico-químicas do recheio dependem diretamente das propriedades da gordura, as quais, portanto, devem cumprir certos pré-requisitos para proporcionar uma estrutura firme, boa incorporação de ar e lubrificação, capacidade de unir os biscoitos para formar o sanduíche, maciez e realce do sabor (GHOTRA et al., 2002; STAUFFER, 2006).

Gomes et al. (2010) avaliaram 15 marcas de biscoitos recheados (sabor chocolate) comercializados no mercado nacional, encontrando uma variação no teor de gordura, nos recheios, de $22,4 \%$ a $32 \%$.

Devido às suas características tecnológicas, ao perfil de sólidos e à curva de cristalização, a gordura hidrogenada foi largamente empregada na produção de biscoitos e seus recheios (MARTIN et al., 2005). No entanto, a gordura hidrogenada tem sido substituída pela indústria de alimentos devido à formação de ácidos graxos trans durante a hidrogenação de óleos vegetais (LIST, 2004).

No Brasil, é obrigatório declarar, no rótulo dos alimentos industrializados, a quantidade de gordura trans, em gramas. A recomendação é de que essa fração seja consumida o mínimo possível, não devendo ultrapassar
$2 \mathrm{~g}$ de gordura trans por dia, considerando uma dieta de $2.000 \mathrm{kcal}$ (UAUY et al., 2009).

Em estudo realizado em 2003, com biscoitos recheados, o teor médio de ácidos graxos trans no biscoito todo, incluindo o recheio, estava em torno de 2,81 a 5,6 g/100 g, valores estes superiores aos limites para ingestão diária em diversos países, incluindo o Brasil (CHIARA et al., 2003). Em outro estudo realizado, com biscoitos recheados comercializados no Brasil, a quantidade de lipídios variou entre 10,21 e 22,72 g/100 g, sendo que 2,61 a 7,96 g/100 g correspondiam aos ácidos graxos saturados e 1,84 a 4,60 g/100 g aos ácidos graxos trans (AUED-PIMENTEL et al., 2003).

Como alternativas, a indústria de óleos e gorduras disponibilizou as gorduras low trans e zero trans. As gorduras low trans podem ser obtidas por processo tecnológico diferente da hidrogenação, como, por exemplo, a interesterificação, que não promove a isomerização de duplas ligações dos ácidos graxos e não afeta o grau de saturação dos mesmos. As gorduras zero trans podem ser obtidas por fracionamento, como no caso da gordura de palma (RIBEIRO et al., 2007).

Desse modo, a indústria de alimentos, procurando atender às expectativas dos consumidores, tem se empenhando na reformulação de produtos, estudando alternativas com perfis lipídicos mais saudáveis, alcançados principalmente pela redução dos índices de gordura trans (FADINI; CRUZ, 2014).

Neste contexto, este estudo visa à caracterização da composição lipídica e à análise das características físicas e sensoriais de recheios de morango em biscoitos encontrados no mercado brasileiro.

\section{Material e métodos}

Foram selecionadas cinco marcas comerciais de biscoitos recheados sabor morango para a caracterização de seus recheios em relação a teor de lipídios, composição em ácidos graxos, atividade de água, diâmetro médio e distribuição de tamanho de partícula, aspecto morfológico e textura. As amostras foram adquiridas em um mesmo estabelecimento, sendo todos os pacotes de cada marca de um mesmo lote; depois, foram codificadas como $A, B, C, D$ e E, preservando o sigilo quanto às marcas. Para todas as determinações, as amostras foram preparadas separando-se cuidadosamente o recheio do biscoito, com auxílio de uma espátula, evitando a presença de fragmentos do biscoito na amostra do recheio e vice-versa.

Após a separação do recheio do biscoito, foram pesadas, em balança semianalítica OHAUS, seis unidades de recheios e seis unidades de biscoitos, sendo a porcentagem de recheio calculada.

A atividade de água dos recheios e dos biscoitos foi determinada utilizando-se o equipamento Decagon 
Devices, modelo AQUA LAB 4TEV, sendo que, para cada amostra, foram realizadas seis leituras.

Os parâmetros de textura avaliados no recheio de biscoito foram firmeza e adesividade, e foram medidos utilizando-se o analisador de textura, de marca Stable Micro Systems, modelo TAXT2i, segundo metodologia adaptada de Queiroz (2010), com as seguintes condições: modo força em compressão, velocidade pré-teste $1,0 \mathrm{~mm} / \mathrm{s}$, velocidade de teste $2,0 \mathrm{~mm} / \mathrm{s}$, velocidade pós-teste: 2,0 $\mathrm{mm} / \mathrm{s}$, distância $30 \mathrm{~mm}$, trigger force button-3g, célula de carga: $50 \mathrm{~kg}$, probe cilíndrico (4 mm) de aço inoxidável. Para cada amostra, foram realizadas 12 replicatas.

A determinação de diâmetro médio e distribuição de tamanho de partícula foi realizada por espalhamento de luz, utilizando-se o equipamento Horiba modelo LV950. As amostras de recheio foram dispersas em óleo mineral e, em seguida, foram analisadas no módulo apropriado para amostras pastosas do equipamento. O diâmetro médio de partícula foi expresso com o diâmetro médio da esfera equivalente, referente a $50 \%$ da distribuição acumulada $\left(\mathrm{D}_{50}\right)$ e a polidispersidade, dada pelo índice span, calculado de acordo com a Fórmula 1:

$$
\text { Span }=\text { D0,9-D0,1/D0,5 }
$$

D0,1, D0,5 e D0,9 correspondem, respectivamente, aos diâmetros referentes a 10\%,50\% e 90\% da distribuição acumulada.

A análise de morfologia dos recheios foi realizada segundo Alvim e Grosso (2010), sendo dispersa uma pequena quantidade de cada amostra em óleo mineral, até adquirir consistência homogênea adequada, e espalhando-a em lâminas para realização da análise morfológica em microscópio da marca Olympus, modelo BX41, e câmera digital Olympus modelo Q-Color3.

Quanto à análise de composição em ácidos graxos, inicialmente realizou-se determinação de lipídios totais das amostras, segundo Zenebon e Pascuet (2005). Em seguida, procedeu-se à preparação dos ésteres metílicos da fração lipídica extraída, de acordo com Hartman e Lago (1973), com posterior quantificação dos ácidos graxos por cromatografia gasosa, com coluna capilar CP Sil 88 e detector de ionização de chama (FID), com base nas metodologias estabelecidas por Firestone (2014) e Horwitz (2010).

A aceitação dos recheios foi avaliada através de um teste afetivo, para o qual foram recrutados, entre funcionários e estagiários do Instituto de Tecnologia de Alimentos, 52 voluntários consumidores de biscoito recheado, sem restrições quanto a idade, sexo e classe social.

As amostras de recheio dos biscoitos adquiridos no comércio foram avaliadas quanto à aceitação da cor, da firmeza, da arenosidade, da cerosidade/sensação de boca untada e do sabor global, por meio de escalas hedônicas de nove pontos ( 9 = gostei muitíssimo, 5 = não gostei nem desgostei e 1 = desgostei muitíssimo). Os termos arenosidade, firmeza e cerosidade foram explicados aos consumidores ao receberem as amostras e, na ficha de avaliação, constava a descrição do termo cerosidade como sensação de boca untada. Quanto à intensidade do sabor de morango e do gosto doce, foram utilizadas escalas do ideal de cinco pontos ( $5=$ muito mais intenso do que eu gosto, 3 = do jeito que eu gosto, 1 = muito menos intenso do que eu gosto), e quanto à atitude de intenção de compra, através de escala de cinco pontos ( 5 = certamente compraria, $3=$ talvez comprasse, talvez não comprasse, 1 = certamente não compraria) (MEILGAARD et al., 2006). Nas escalas de cinco pontos, as notas 5 e 4 foram contabilizadas como acima do ideal ou intenção positiva de compra; a nota 3, como ideal ou intenção de compra neutra, e as notas 2 e 1, como abaixo do ideal ou intenção de compra negativa. Além disso, foi solicitado aos voluntários que indicassem as razões pelas quais mais gostaram e menos gostaram das amostras avaliadas. As amostras foram avaliadas de forma monádica sequencial, segundo um delineamento de blocos completos aleatorizados, e apresentadas com códigos de três números aleatórios, servidas à temperatura ambiente, em pratos descartáveis. Foi oferecida água mineral natural para uso antes e entre as amostras, visando dessensibilizar o paladar de qualquer outra impressão que não aquela própria da amostra a ser avaliada. Os biscoitos recheados foram apresentados abertos, em uma das bases, de modo que o recheio ficasse aparente e os avaliadores fossem solicitados a consumir apenas o recheio.

O teste foi conduzido em cabines individuais, com iluminação de lâmpadas fluorescentes equipadas com o sistema computadorizado Compusense Five versão 5.6, para coleta e análise dos dados. Os dados relativos às escalas utilizadas, assim como aqueles relativos às análises físicas, foram submetidos à análise de variância e teste de Tukey, para comparação de médias no nível de confiança de $95 \%(p \leq 0,05)$, tendo sido também calculado o coeficiente de correlação de Pearson. Com o objetivo de identificar algumas direções possíveis para a melhoria do produto, em relação a quanto os consumidores gostaram do sabor de seu recheio, as escalas de intensidade ideal (sabor de morango e gosto doce) foram analisadas por penalidades, no mesmo intervalo de confiança de $95 \%$. Para tal, adotou-se o critério de que o tamanho do grupo, seja o que julgou acima ou abaixo do ideal, deveria ser composto de pelo menos 20 consumidores (VARELA; ARES, 2014).

\section{Resultados e discussão}

De acordo com o resultado obtido da porcentagem de recheio no biscoito tipo sanduíche das marcas comerciais selecionadas (Tabela 1), apenas uma marca 
Tabela 1. Peso da unidade de biscoito com recheio e somente do recheio.

\begin{tabular}{cccc} 
Amostra & Biscoito com recheio $(\mathbf{g})$ & Recheio $(\mathbf{g})$ & Recheio no biscoito (\%) \\
A & $11,34 \pm 0,24^{\mathrm{b}}$ & $3,44 \pm 0,20^{\mathrm{b}}$ & $30,28 \pm 1,18^{\mathrm{a}}$ \\
B & $11,36 \pm 0,11^{\mathrm{b}}$ & $3,57 \pm 0,12^{\mathrm{b}}$ & $31,44 \pm 1,30^{\mathrm{a}}$ \\
C & $11,36 \pm 0,34^{\mathrm{b}}$ & $3,44 \pm 0,32^{\mathrm{b}}$ & $30,20 \pm 1,94^{\mathrm{a}}$ \\
D & $13,33 \pm 0,18^{\mathrm{a}}$ & $3,34 \pm 0,22^{\mathrm{b}}$ & $25,06 \pm 1,84^{\mathrm{b}}$ \\
E & $13,24 \pm 0,05^{\mathrm{a}}$ & $3,96 \pm 0,05^{\mathrm{a}}$ & $29,93 \pm 0,29^{\mathrm{a}}$ \\
\hline
\end{tabular}

Médias e desvios padrões seguidos de letra igual na mesma coluna não diferem significativamente entre si pelo teste de Tukey a $5 \%$ de probabilidade.

comercial apresentou valor estatisticamente diferente das demais ( $p \leq 0,05)$, com $25 \%$ de recheio; as outras marcas apresentaram valores entre 29 e $31 \%$. O peso do recheio é normalmente cerca de $25 \%$ do biscoito recheado, mas quantidades entre 15 e $36 \%$ podem ser encontradas; em geral, quanto maior o biscoito, menor o percentual de creme (MANLEY, 1998).

Após a separação dos recheios dos biscoitos e a realização de análise de atividade de água, os resultados obtidos para os biscoitos (Tabela 2) apresentaram-se abaixo de 0,6; tais valores são considerados seguros quanto ao crescimento microbiano (TROLLER, 1980), variando entre 0,2659 e 0,3089. Os resultados de atividade de água dos recheios tiveram uma variação entre 0,471 e 0,506, valores também inferiores a 0,6. A atividade de água dos biscoitos e recheios deve ser baixa para que não ocorra a perda da estabilidade microbiológica do produto nem a perda de crocância do biscoito (KIM et al., 1999). Observe-se que atividades de água acima de 0,4 podem provocar perda de crocância do biscoito (LABUZA et al., 2004). Grande diferença entre os valores de atividade de água dos recheios e dos biscoitos favorecem a troca de umidade entre eles, ocasionando a absorção de umidade e a perda de crocância do biscoito, além de, por outro lado, causar o ressecamento do recheio (LEITE et al., 2005).

Os valores obtidos na análise de textura instrumental possuem como resposta os parâmetros firmeza e adesividade, apresentados na Tabela 3. Um dos recheios (D) foi o mais firme, 124,04 gf, diferindo significativamente de todos os demais $(p \leq 0,05)$. Os recheios $A$ e $C$ não diferiram significativamente entre si $(p>0,05)$ quanto à firmeza, obtendo os menores valores. O recheio deve ser firme para que não saia quando pressionado na etapa de montagem do biscoito recheado e também não provoque deslizamento do biscoito durante o transporte ou o consumo do produto, mantendo assim a estrutura de "sanduíche" do biscoito recheado (GHOTRA et al., 2002; STAUFFER, 2006). De modo paralelo, podemos sugerir que quanto maior a adesividade, maior é a tendência de manutenção da estrutura do biscoito recheado.

Quanto à adesividade, o recheio $D$ foi o que obteve o maior valor, diferindo $(p \leq 0,05)$ de todos os outros; em seguida, está o recheio $B$, também diferindo $(p \leq 0,05)$ dos demais. Os recheios $A, C$ e E obtiveram valores inferiores a 110 gf, não diferindo significativamente entre si $(p>0,05)$.
Tabela 2. Atividade de água dos biscoitos e seus recheios.

\begin{tabular}{ccc} 
Biscoitos & \multicolumn{2}{c}{ Aw (média e desvio) } \\
\cline { 2 - 3 } comerciais & Biscoito & Recheio \\
A & $0,3089 \pm 0,0174^{\mathrm{b}}$ & $0,4745 \pm 0,0193^{\mathrm{c}}$ \\
B & $0,2808 \pm 0,0036^{\mathrm{c}}$ & $0,4972 \pm 0,0125^{\mathrm{ab}}$ \\
C & $0,2682 \pm 0,0061^{\mathrm{cd}}$ & $0,4705 \pm 0,0081^{\mathrm{c}}$ \\
D & $0,2659 \pm 0,0022^{\mathrm{d}}$ & $0,5062 \pm 0,0039^{\mathrm{a}}$ \\
E & $0,3427 \pm 0,0042^{\mathrm{a}}$ & $0,4819 \pm 0,0066^{\mathrm{bc}}$ \\
\hline
\end{tabular}

Médias e desvios padrões seguidos de letra igual na mesma coluna não diferem significativamente entre si pelo teste de Tukey a 5\% de probabilidade.

Tabela 3. Firmeza e adesividade dos recheios de biscoitos comerciais.

\begin{tabular}{ccc}
$\begin{array}{c}\text { Biscoitos } \\
\text { comerciais }\end{array}$ & Firmeza (gf) & Adesividade (gf) \\
\hline A & $37,41 \pm 1,47^{\mathrm{d}}$ & $108,11 \pm 5,14^{\mathrm{a}}$ \\
B & $94,85 \pm 6,51^{\mathrm{b}}$ & $193,86 \pm 9,87^{\mathrm{b}}$ \\
C & $39,85 \pm 2,99^{\mathrm{d}}$ & $101,66 \pm 7,97^{\mathrm{a}}$ \\
D & $124,04 \pm 8,45^{\mathrm{a}}$ & $255,78 \pm 17,54^{\mathrm{c}}$ \\
E & $56,06 \pm 2,73^{\mathrm{c}}$ & $98,45 \pm 8,46^{\mathrm{a}}$ \\
\hline
\end{tabular}

Médias e desvios padrões seguidos de letra igual na mesma coluna não diferem significativamente entre si pelo teste de Tukey a 5\% de probabilidade.

O recheio $E$ foi o que obteve o maior diâmetro médio de partícula (Figura 1a) e a menor polidispersidade (Figura 1b), embora todas as amostras tenham apresentado valores altos de span - entre 3,2 e 7,8 -, indicando alta variação de tamanho das partículas sólidas presentes nas amostras. Os valores de $D_{90}$ (diâmetro referente para 90\% da distribuição acumulada da amostra), em micrômetros, determinados para as amostras foram: A - 80,5 $\pm 5,9$; B - 102,4 $\pm 6,7 ;$ C $-145,5 \pm 13,0 ; D-151,4 \pm 2,8$; e $\mathrm{E}-79,5 \pm 7,3$, indicando que todas as amostras apresentaram partículas de tamanhos grandes, o que pode influenciar na característica sensorial de arenosidade. Na análise morfológica dos cinco recheios de biscoito comerciais, foram captadas imagens (Figura 2) que reforçaram os resultados de distribuição de tamanho (span), com polidispersidade evidente e característica desse tipo de produto, com a presença de cristais de açúcar e bolhas de ar geradas durante a mistura e o batimento do recheio.

O teor de lipídios totais dos recheios (Tabela 4) variou de $22,79 \%$ (recheio $\mathrm{E}$ ) a 33,15\% (recheio D), sendo 
Composição lipídica, características físicas e sensoriais de recheios de morango em biscoitos

Akamine, E. H. et al.
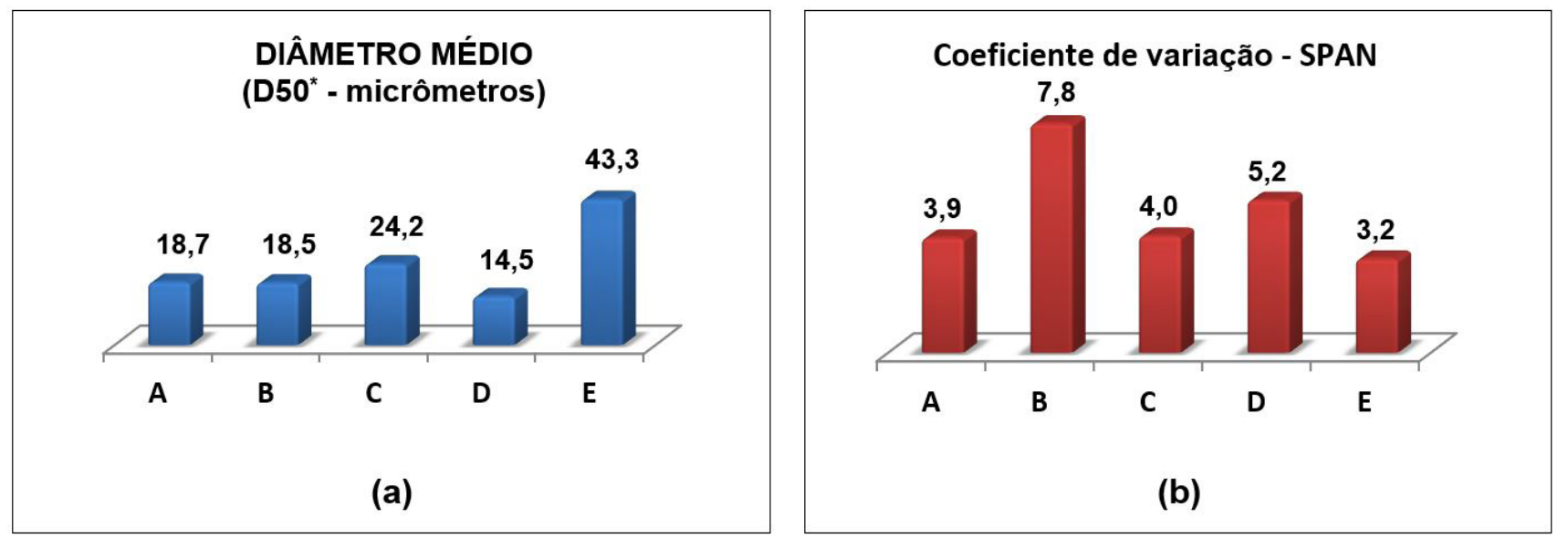

Figura 1. Diâmetro médio de partícula $\left(D_{50}{ }^{*}\right.$ - diâmetro equivalente a 50\% da distribuição) (a) e coeficiente de variação (polidispersidade / índice span) (b) dos recheios comerciais A, B, C, D e E.
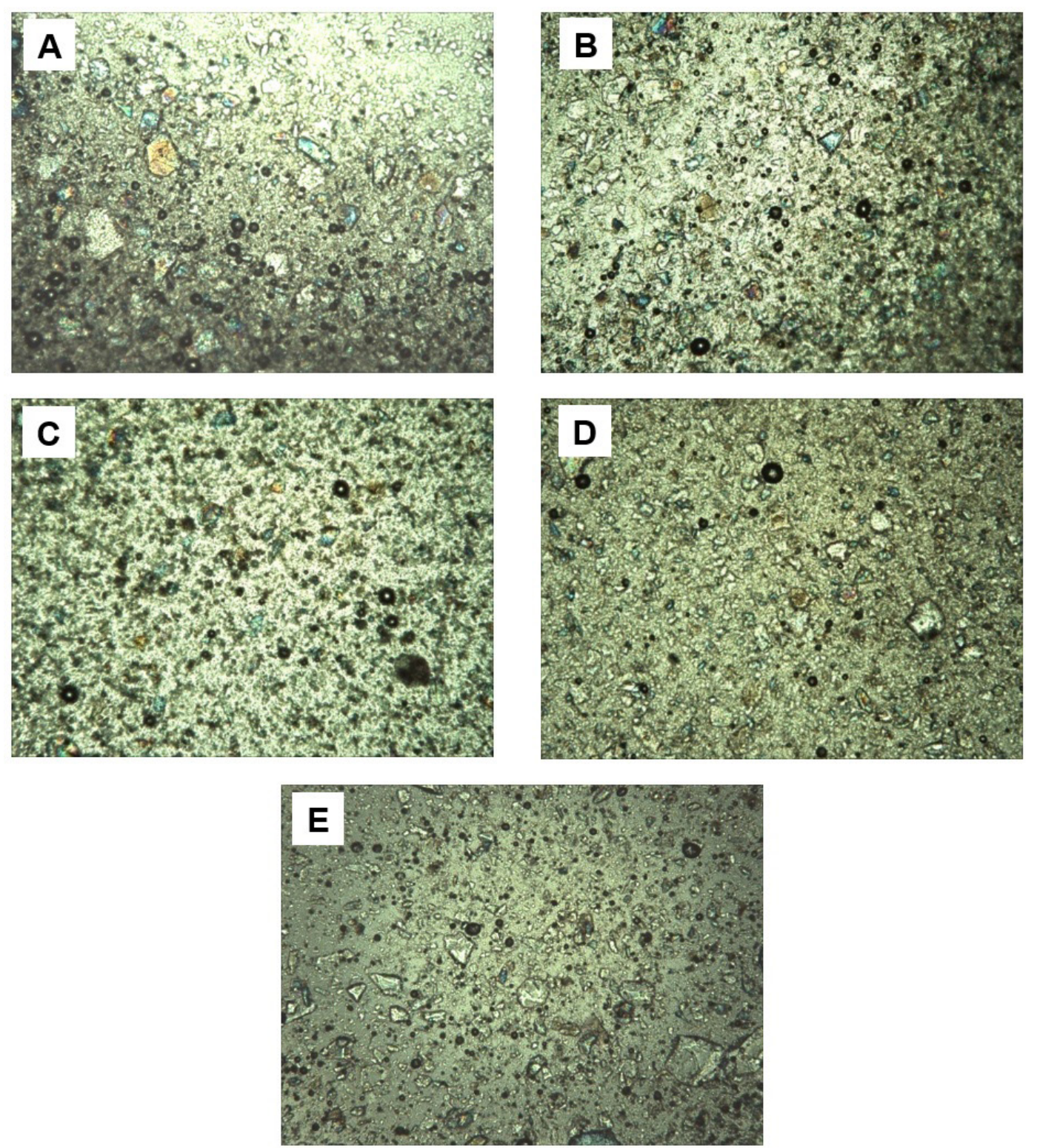

Figura 2. Morfologia de amostras de recheios comerciais: (A) Recheio Comercial A; (B) Recheio Comercial B; (C) Recheio Comercial C; (D) Recheio Comercial D; (E) Recheio Comercial E. Todas as imagens foram obtidas em aumento de 1.000 vezes. 
Tabela 4. Composição em ácidos graxos e determinação de lipídios totais dos recheios sabor morango de biscoitos comerciais (A, B, C, D e E).

\begin{tabular}{|c|c|c|c|c|c|c|}
\hline & \multirow{2}{*}{$\begin{array}{l}\text { Lipídios totais } \\
\qquad(\mathrm{g} / 100 \mathrm{~g})^{\mathrm{a}}\end{array}$} & \multirow{2}{*}{$\frac{A}{28,35(0,21)}$} & \multirow{2}{*}{$\frac{B}{26,71(0,13)}$} & \multirow{2}{*}{$\begin{array}{c}\text { C } \\
26,32(0,02)\end{array}$} & \multirow{2}{*}{$\frac{\text { D }}{33,15(0,09)}$} & \multirow{2}{*}{$\begin{array}{c}E \\
22,79(0,4)\end{array}$} \\
\hline & & & & & & \\
\hline \multirow{7}{*}{$\begin{array}{l}\text { Ácidos Graxos } \\
\text { (g/100 g) }\end{array}$} & Saturados & 14,56 & 10,93 & 13,08 & 17,01 & 10,24 \\
\hline & Monoinsaturados & 6,45 & 10,41 & 8,52 & 10,09 & 3,89 \\
\hline & Poli-insaturados & 5,06 & 3,44 & 3,17 & 4,04 & 7,49 \\
\hline & Ômega 3 & 0,1 & 0,05 & 0,14 & 0,16 & 0,2 \\
\hline & Ômega 6 & 4,96 & 3,39 & 3,03 & 3,88 & 7,29 \\
\hline & Trans-isômeros totais & 1,02 & 0,75 & 0,42 & 0,55 & 0,15 \\
\hline & N.I. & 0,02 & & & & \\
\hline \multirow{20}{*}{$\begin{array}{l}\text { Composição em } \\
\text { ácidos graxos } \\
(\mathrm{g} / 100 \mathrm{~g})^{\mathrm{b}}\end{array}$} & C 8:0 caprílico & 0,05 & & 0,02 & 0,03 & \\
\hline & C 10:0 cáprico & 0,05 & & 0,02 & 0,03 & \\
\hline & C 12:0 láurico & 0,8 & 0,15 & 0,25 & 0,37 & 0,17 \\
\hline & C 14:0 mirístico & 0,49 & 0,19 & 0,28 & 0,29 & 0,19 \\
\hline & C 16:0 palmítico & 10,78 & 7,18 & 9,73 & 11,47 & 5,74 \\
\hline & C 16:1 ômega 7 palmitoleico & 0,04 & 0,04 & 0,03 & & 0,04 \\
\hline & ômega 7 & & & & 0,03 & \\
\hline & C 17:0 margárico & 0,03 & 0,02 & 0,03 & 0,03 & 0,03 \\
\hline & C 18:0 esteárico & 2,19 & 3,19 & 2,6 & 4,58 & 4 \\
\hline & C 18:1 ômega 9 trans elaídico & 0,63 & 0,58 & 0,34 & 0,4 & \\
\hline & C 18:1 ômega 9 oleico & 6,36 & 10,33 & 8,44 & 9,99 & 3,82 \\
\hline & C 18:2 ômega 6 trans t-linoleico & 0,37 & 0,17 & 0,08 & 0,12 & 0,15 \\
\hline & C 18:2 ômega 6 linoleico & 4,96 & 3,39 & 3,03 & 3,88 & 7,29 \\
\hline & C 20:0 araquídico & 0,1 & 0,09 & 0,1 & 0,13 & 0,08 \\
\hline & C 18:3 ômega 3 trans t-linolênico & 0,02 & & & 0,03 & \\
\hline & C 20:1 ômega 11 cis-11-eicosenoico & 0,05 & 0,04 & 5 & 0,07 & 0,03 \\
\hline & C 18:3 ômega 3 & 0,1 & 0,05 & 0,14 & 0,16 & 0,2 \\
\hline & N.I. & 0,02 & & & & \\
\hline & C 22:0 behênico & 0,04 & 0,07 & 0,03 & 0,05 & 0,03 \\
\hline & C 24:0 lignocérico & 0,03 & 0,04 & 0,02 & 0,03 & \\
\hline
\end{tabular}

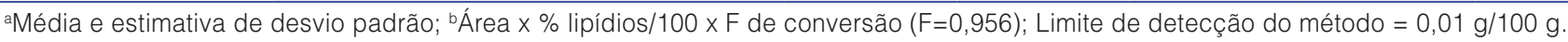

a média encontrada de $27,5 \%$ de lipídios nos recheios das cinco marcas comerciais. Esse valor está próximo do valor indicado por Manley (1998), de 30\% de gordura em formulações usuais de recheios de biscoito, e por Gomes et al. (2010), que avaliaram o teor de gordura em 15 recheios de biscoitos comerciais e encontraram o valor médio de $28,6 \%$.

O recheio com maior teor lipídico (D) foi o que apresentou maior teor de ácidos graxos saturados (17,1 g/100 g) e de ácidos graxos insaturados $(14,13 \mathrm{~g} / 100 \mathrm{~g})$, dentre os recheios comerciais analisados. O ácido palmítico (C 16:0) e o ácido oleico (C 18:1 ômega 9) foram os de maior predominância dentre os saturados e insaturados, respectivamente. Esse recheio também foi o que apresentou o maior teor de gordura, $33,15 \%$, e foi avaliado como o mais firme (124,04 gf) e o mais adesivo (255,78 gf). A maior firmeza desse recheio poderia estar associada ao maior teor em ácidos graxos saturados da gordura utilizada, visto que a gordura é um dos principais responsáveis pela estrutura do recheio (GHOTRA et al., 2002; STAUFFER, 2006), porém essa correlação é fraca positiva $(r=0,4)$, quando realizada a análise de correlação de Pearson. No entanto, foi observada uma correlação moderada positiva $(r=0,6)$ para avaliação em relação ao teor de lipídios e a firmeza.

Por outro lado, o recheio E, com menor teor lipídico, foi o que apresentou menor teor de ácidos saturados $(10,24 \mathrm{~g} / 100 \mathrm{~g})$ e também de insaturados $(11,38 \mathrm{~g} / 100 \mathrm{~g})$, com maior teor de ácido palmítico (C 16:0) e ácido linoleico (C: 18:2 ômega 6), respectivamente. Note-se que esse recheio não apresentou a menor firmeza (56,47 gf).

Os ácidos presentes em maior proporção, em todos os recheios, são: palmítico (C 16:0), esteárico (C 18:0), oleico (C 18:1 ômega 9) e linoleico (C 18:2 ômega 6). O ácido palmítico é fundamental em produtos plásticos, sendo um dos responsáveis pela tendência de cristalização na forma $\beta^{\prime}$, que é importante para produtos que requerem boa capacidade de aeração, além de proporcionar cremosidade. Teores de ácido palmítico acima de 20\% na fração lipídica do recheio revelam um forte indício da presença de óleos de palma e/ou algodão (GRIMALDI et al., 2000). 
Os valores de ácidos graxos trans na fração lipídica dos recheios variaram de $0,71 \%$ (recheio $E$ ) a $3,78 \%$ (recheio A), valores bem abaixo daqueles encontrados por Grimaldi et al. (2000) para gorduras comerciais destinadas a biscoitos recheados, de 19,5 a 48,3\%, indicando que a indústria de biscoitos tem reduzido a utilização de gorduras trans em seus produtos, na última década. A maneira mais eficaz de reduzir ácidos graxos trans em biscoitos é monitorar a gordura utilizada na sua fabricação (KALA, 2014).

Os valores de ácidos graxos trans nas amostras de recheio variaram de $0,15 \%$ (recheio $E$ ) a $1,02 \%$ (recheio A), valores abaixo daqueles encontrados por Aued-Pimentel et al. (2003) e por Chiara et al. (2003), nas faixas de $2,31 \%$ a $4,11 \%$ e $2,86 \%$ de gorduras trans, respectivamente, em biscoitos recheados sabor morango comercializados no Brasil; mostraram-se também abaixo daqueles encontrados por Kala (2014), de 1,1\% a 1,3\%, em biscoitos recheados sabor morango do mercado indiano. Os valores encontrados neste estudo estão de acordo com o limite da Organização Mundial de Saúde - OMS, que menciona que a ingestão máxima diária desses ácidos graxos seja calculada como 1\% de uma dieta de 2.000 cal, o que equivaleria a 2 g/dia (PALM OIL LINK, 2003).

Porém, para os ácidos graxos saturados totais encontrados (10,24 g/100 g a 17,01 g/100 g), os valores estão acima do valor recomendado pelas organizações OMS e FAO - Food Agriculture Organization, que mencionam que não mais de $10 \%$ do total de energia consumida deve ser fornecido pela gordura saturada (FAO, 2008). Os valores obtidos neste estudo estão acima daqueles encontrados por Aued-Pimentel et al. (2003) para biscoitos recheados sabor morango, entre $4,22 \%$ a $7,62 \%$ de ácidos graxos saturados, e próximos aos valores reportados por Kala (2014), entre 13,7\% e 16,6\%. Esses dados sugerem que a indústria de biscoitos tem substituído a gordura hidrogenada por gordura à base de palma, o que já foi observado na avaliação dos teores de ácido palmítico nas frações lipídicas dos recheios.

Quanto à avaliação sensorial, o grupo de consumidores recrutados foi composto por 52 consumidores de biscoito, apreciadores de biscoito recheado, sendo 11 homens e 41 mulheres. As características quanto à faixa etária e os tipos de biscoito mais consumidos pelo grupo são apresentadas na Figura 3. O tipo de biscoito indicado como o mais consumido pelos consumidores foi o recheado, corroborando com informações apresentadas pela Associação Brasileira das Indústrias de Biscoitos, Massas Alimentícias e Pães \& Bolos Industrializados, que indicam que o biscoito recheado é o mais vendido no Brasil (ABIMAPI, 2015).

Os resultados médios obtidos no teste de aceitação da cor, da firmeza, da arenosidade, da cerosidade (sensação de "boca untada") e do sabor global são apresentados na Tabela 5. Verificou-se que todas as amostras foram bem aceitas quanto à firmeza e ao sabor, sem diferirem significativamente entre si $(p \leq 0,05)$, tendo recebido médias próximas de "gostei" para a firmeza e entre "gostei" e "gostei pouco" para o sabor.

Em relação à aceitação da cor dos recheios, as amostras A, C, D e E foram as mais aceitas e receberam médias entre "gostei muito" e "gostei" na escala utilizada, diferindo no nível de $5 \%$ da amostra B, que recebeu média correspondente a "não gostei, nem desgostei"; observou-se que essa amostra apresentou recheio com menor intensidade e uniformidade de cor rósea.

Quanto à avaliação da aceitação da arenosidade, as amostras A, B, C e D foram mais aceitas e receberam médias correspondentes a "gostei" na escala utilizada, diferindo no nível de $5 \%$ da amostra $E$, que recebeu média entre "gostei pouco" e "não gostei, nem desgostei". A amostra $E$ foi a que apresentou o maior diâmetro médio de partícula (Figura 1A), apresentando uma correlação
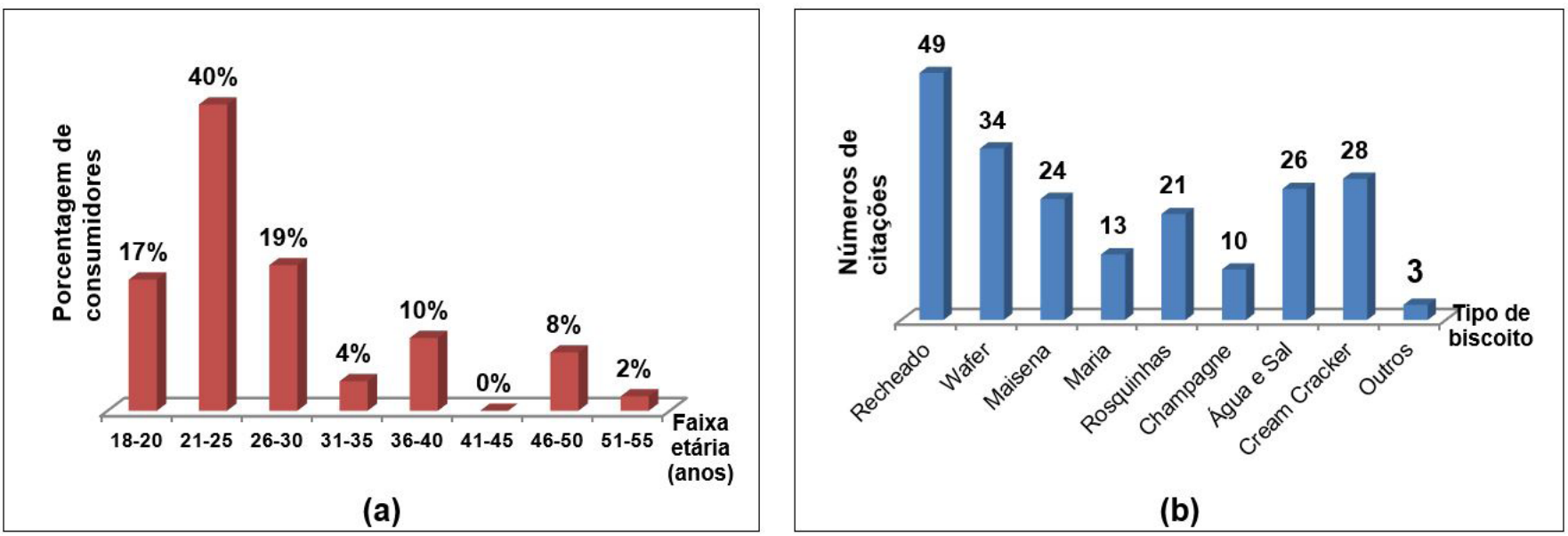

Figura 3. Faixa etária dos consumidores (a) e tipos de biscoito mais consumidos (b) pelo grupo de consumidores recrutados para avaliação das amostras. 
perfeita negativa $(r=-1)$, ou seja, quanto maior o diâmetro médio de partícula, menor a aceitação da arenosidade do recheio. De acordo com Linden e Lorient (1996), recheios que não apresentam sensação de arenosidade são aqueles com partículas menores que $30 \mu \mathrm{m}$ e a amostra $\mathrm{E}$ foi aquela que apresentou diâmetro médio superior a esse valor limite. A ausência de arenosidade em recheio de biscoito é um dos atributos que predominam na preferência do consumidor de biscoito recheado (ORMENESE et al., 2001), o que foi confirmado nesse trabalho.

Em relação à aceitação da cerosidade, a amostra $D$, que apresentou maior teor lipídico, com predominância de ácido palmítico e oleico, foi avaliada com média correspondente a "gostei", sendo mais aceita ( $p \leq 0,05)$ que $A$ e $E$, as quais apresentaram médias próximas de "gostei pouco" e não diferiram significativamente entre si $(p>0,05)$. As amostras B e C não diferiram entre si $(p>0,05)$ e nem de $D$ e de E. Através da análise de Pearson, verificou-se uma correlação forte positiva $(r=0,8)$ entre os teores de ácidos graxos monoinsaturados e a aceitação da cerosidade.

Os percentuais de intensidade maior que a desejada (notas de 5 a 4), intensidade desejada (nota 3) e intensidade menor que a desejada (notas 2 e 1); os valores, também em porcentagem, de intenção positiva de compra (notas 5 a 4), dúvida de compra (nota 3) e intenção negativa de compra (notas 2 e 1) são apresentados na Tabela 6.

Quanto às porcentagens de intensidade do sabor de morango e do gosto doce, observou-se que, em geral, as amostras apresentaram porcentagens de intensidade de acordo com o gosto dos consumidores acima de $45 \%$, com alguma superioridade para as amostras B, C, D e E, enquanto a amostra $A$ apresentou $61 \%$ de intensidade do sabor de morango abaixo do ideal. Na análise de penalidades realizada para cada amostra de recheio, quando as amostras A, B, C e E foram avaliadas pelos consumidores (20 ou mais) como sabor de morango menos intenso do que o ideal, houve redução significativa na aceitação quanto ao sabor do recheio, que impactou em 1,9; 2,7; 1,3 e 1,9 pontos a menos nessa aceitação, respectivamente. O mesmo foi observado para o dulçor mais intenso que o ideal, para a amostra B, que impactou significativamente em 1,4 ponto a menos na aceitação do sabor do recheio. A amostra D não se encaixou no critério adotado (pelo menos 20 consumidores avaliando como mais ou menos intenso que o ideal) e não foi analisada por penalidades.

Quanto à intenção de compra dos consumidores, observou-se que as amostras B, C, D e E obtiveram porcentagens de intenção positiva de compra acima de $57 \%$, enquanto a amostra $A$ apresentou apenas $32,7 \%$ de intenção de compra.

Os principais comentários obtidos dos consumidores para as amostras, quando questionados sobre do que mais gostaram e do que menos gostaram, são apresentados nas Tabelas 7 e 8. Observou-se que a amostra D recebeu maior número de menções positivas e também recebeu o menor número de menções negativas, seguida da amostra $\mathrm{C}$.

Tabela 5. Médias da aceitação do recheio de biscoito sabor morango quanto aos atributos cor, firmeza, arenosidade, cerosidade e sabor* de biscoitos comerciais (A, B, C, D e E).

\begin{tabular}{lcccccc}
\multicolumn{1}{c}{$\begin{array}{c}\text { Atributos } \\
\text { sensoriais }\end{array}$} & A & B & C & D & E & DMS \\
Cor & $7,8 \pm 0,8^{\mathrm{a}}$ & $5,0 \pm 2,3^{\mathrm{b}}$ & $7,9 \pm 0,8^{\mathrm{a}}$ & $7,4 \pm 1,3^{\mathrm{a}}$ & $7,4 \pm 1,2^{\mathrm{a}}$ & 0,7 \\
Firmeza & $7,2 \pm 1,2^{\mathrm{a}}$ & $7,4 \pm 1,3^{\mathrm{a}}$ & $7,5 \pm 1,1^{\mathrm{a}}$ & $7,2 \pm 1,6^{\mathrm{a}}$ & $7,0 \pm 1,6^{\mathrm{a}}$ & 0,6 \\
Arenosidade & $6,8 \pm 1,4^{\mathrm{a}}$ & $6,8 \pm 1,7^{\mathrm{a}}$ & $6,8 \pm 1,2^{\mathrm{a}}$ & $7,0 \pm 1,3^{\mathrm{a}}$ & $5,7 \pm 2,1^{\mathrm{b}}$ & 0,8 \\
Cerosidade $^{\star \star}$ & $5,7 \pm 1,9^{\mathrm{c}}$ & $6,8 \pm 1,4^{\mathrm{ab}}$ & $6,7 \pm 1,5^{\mathrm{ab}}$ & $7,2 \pm 1,3^{\mathrm{a}}$ & $6,2 \pm 1,9^{\mathrm{bc}}$ & 0,8 \\
Sabor & $6,2 \pm 1,6^{\mathrm{a}}$ & $6,3 \pm 2,1^{\mathrm{a}}$ & $6,7 \pm 1,5^{\mathrm{a}}$ & $6,8 \pm 1,9^{\mathrm{a}}$ & $6,5 \pm 1,6^{\mathrm{a}}$ & 0,9 \\
\hline
\end{tabular}

${ }^{*}$ Resultado expresso como média \pm desvio-padrão, utilizando escala de nove pontos. Para cada atributo (linha), valores seguidos de letras iguais não diferem estatisticamente entre si no nível de erro de $5 \%$; * Sensação de boca "untada". D.M.S.: Diferença mínima significativa no nível de erro de $5 \%$ (Teste de Tukey).

Tabela 6. Porcentagens de intensidade acima, abaixo e ideal, e intenção de compra positiva, negativa e neutra de recheios de biscoitos comerciais (A, B, C, D e E).

\begin{tabular}{llrrrrr}
\multicolumn{2}{c}{ Parâmetros de intensidade e intenção } & A & B & C & D & E \\
\multirow{3}{*}{ Intensidade do sabor de morango } & Acima do ideal (\%) & 5,8 & 11,5 & 9,6 & 21,2 & 7,7 \\
& Ideal (\%) & 32,7 & 46,2 & 51,9 & 61,5 & 51,9 \\
& Abaixo do ideal (\%) & 61,5 & 42,3 & 38,5 & 17,3 & 40,4 \\
\multirow{3}{*}{ Intensidade do gosto doce } & Acima do ideal (\%) & 13,5 & 40,4 & 23,1 & 27,0 & 34,7 \\
& Ideal (\%) & 61,5 & 53,9 & 65,4 & 63,5 & 57,7 \\
& Abaixo do ideal (\%) & 25,0 & 5,8 & 11,6 & 9,6 & 7,7 \\
Intenção de compra & Positiva (\%) & 32,7 & 59,7 & 61,5 & 61,6 & 57,7 \\
& Neutra (\%) & 36,5 & 13,5 & 21,2 & 17,3 & 15,4 \\
& Negativa (\%) & 30,8 & 26,9 & 17,3 & 21,2 & 27,0 \\
\hline
\end{tabular}


Tabela 7. Frequência do termo citado como razão pela qual o consumidor mais gostou dos recheios de biscoitos comerciais sabor morango ( $A, B, C, D$ e $E)$.

\begin{tabular}{|c|c|c|c|c|c|}
\hline Razões pelas quais mais gostou & A & B & C & D & E \\
\hline Aroma & 1 & 3 & 1 & 1 & 3 \\
\hline Sabor & 17 & 28 & 27 & 27 & 26 \\
\hline Textura/cerosidade/gordura & 12 & 19 & 17 & 22 & 9 \\
\hline Aparência/cor (rósea) & 19 & 2 & 2 & 15 & 20 \\
\hline Tudo & 2 & 1 & 14 & 4 & 1 \\
\hline Total de menções & 51 & 53 & 61 & 69 & 59 \\
\hline
\end{tabular}

Tabela 8. Frequência do termo citado como razão pela qual o consumidor mais desgostou dos recheios de biscoitos comerciais sabor morango ( $A, B, C, D$ e E).

\begin{tabular}{lccccc}
\multicolumn{1}{c}{ Razões pelas quais menos gostou } & A & B & C & D & E \\
Aroma & 1 & 1 & - & 21 & 21 \\
Sabor & 37 & 28 & 22 & 12 & 64 \\
Textura/cerosidade/gordura & 21 & 11 & 1 & 2 & 2 \\
Aparência/ cor (rósea) & - & 19 & 4 & 6 & 2 \\
Tudo & - & 3 & $\mathbf{4 8}$ & $\mathbf{4 2}$ & $\mathbf{1 0 0}$ \\
Total de menções & $\mathbf{5 9}$ & $\mathbf{6 2}$ &
\end{tabular}

Os pontos positivos apontados para a amostra D concordam com a melhor avaliação obtida por essa amostra quanto à arenosidade e à sensação na boca, de acordo com os valores mostrados na Tabela 6 . Essa amostra também foi a que apresentou maior teor de ácido palmítico (C 16:0), componente que facilita a obtenção de maior cremosidade em produtos aerados, segundo Grimaldi et al. (2000). A amostra E, que apresentou o menor teor lipídico, foi aquela que recebeu o maior número de menções negativas, principalmente em relação à textura e à cerosidade do recheio. Essa amostra foi a que recebeu a menor nota quanto à aceitação da arenosidade, o que pode ser explicado pelo seu maior diâmetro médio de partícula.

\section{Conclusões}

Os cinco recheios comerciais avaliados apresentaram pouca variação de Aw, valores de 0,47 a 0,50. O recheio que apresentou o maior diâmetro médio de partícula foi o menos aceito quanto à arenosidade. Possivelmente, a característica e/ou a quantidade do açúcar presente no recheio tenha interferido na aceitação quanto à arenosidade, uma vez que apresentou elevada porcentagem de gosto doce acima do ideal, embora o ideal de adoçamento de todas as amostras não tenha impactado no gostar do sabor do recheio de cada uma das amostras avaliadas por penalidades. Quanto à firmeza instrumental, houve maior variação entre as marcas comerciais, embora não tenha interferido na aceitação da firmeza avaliada pelos consumidores. Da mesma forma, houve variação na composição em ácidos graxos, indicando diferentes fontes lipídicas das gorduras destinadas a recheios. O teor médio de lipídios encontrado, 27,5\%, foi próximo ao da literatura, que cita 30\%. O valor médio de ácidos graxos trans foi inferior aos valores relatados em literatura de 2003, confirmando que a indústria vem reduzindo esses teores; observou-se, porém, que os valores de ácidos graxos saturados ainda são altos. As diferentes fontes lipídicas nas gorduras destinadas a recheios interferiram na aceitação de arenosidade e cerosidade percebidas pelos consumidores, e quanto maiores os teores de ácidos graxos monoinsaturados, maior foi a aceitação desses atributos. As médias de aceitação para arenosidade sugerem que os consumidores ainda preferem biscoitos com maior teor de lipídios. A maior intenção de compra verificada foi para o produto $C$, que apresentou características intermediárias quanto a Aw, firmeza, adesividade e composição em ácidos graxos. Esse produto se destacou em relação aos demais por não apresentar penalidades significativas nos critérios avaliados, pela boa aceitação e pela boa percentagem de intenção positiva de compra, além de ser uma das marcas mais conhecidas no País.

\section{Agradecimentos}

Ao CNPq pela concessão de bolsa de iniciação científica PIBIC.

\section{Referências}

ALVIM, I. D.; GROSSO, C. R. F. Microparticles obtained by complex coacervation: influence of the type of reticulation and the drying process on the release of the core material. Ciência e Tecnologia de Alimentos, Campinas, v. 30, n. 4, p. 1069-1076, 2010. http://dx.doi.org/10.1590/S0101-20612010000400036.

ASSOCIAÇÃO BRASILEIRA DAS INDÚSTRIAS DE BISCOITOS, MASSAS ALIMENTÍCIAS E PÃES \& BOLOS INDUSTRIALIZADOS 
Composição lipídica, características físicas e sensoriais de recheios de morango em biscoitos

Akamine, E. H. et al.

- ABIMAPI. Anuário ABIMAPI 2015. São Paulo: Editora Definição, 2015. Disponível em: <http://abima.com.br/cloud/ ABIMAPI_ANUARIO_2015.pdf>. Acesso em: 29 maio 2015.

AUED-PIMENTEL, S.; CARUSO, M. S. F.; CRUZ, J. M. M.; KUMAGAI, E. E.; CÔRREA, U. O. Ácidos graxos saturados versus ácidos graxos trans em biscoitos. Revista do Instituto Adolfo Lutz, São Paulo, v. 62, n. 2, p. 131-137, 2003.

CHIARA, V. L.; SICHIERI, R.; CARVALHO, T. S. F. Teores de ácidos graxos trans de alguns alimentos consumidos no Rio de Janeiro. Revista de Nutrição, Campinas, v. 16, n. 2, p. 227-233, 2003. http://dx.doi.org/10.1590/S1415-52732003000200010.

FADINI, A. L.; CRUZ, C. L. C. V. Controle e adequação. In: QUEIROZ, G. C.; REGO, R. A.; JARDIM, D. C. P. Brasil bakery \& confectionery trends 2020. Campinas: ITAL, 2014. cap. 4, p. 73-115.

FIRESTONE, D. (Ed.). Official methods and recommended practices of the American Oil Chemists Society. 6th ed. Champaign: AOCS Press, 2014.

FOOD AND AGRICULTURE ORGANIZATION - FAO. Fats and fatty acids in human nutrition: report of an expert consultation. Geneva, 2008. 189 p. (Food and Nutrition Paper, 91).

GHOTRA, B. S.; DYAL, S. D.; NARINE, S. S. Lipid shortenings: a review. Food Research International, Oxford, v. 35, n. 10, p. 1015-1048, 2002. http://dx.doi.org/10.1016/S0963-9969(02)00163-1.

GOMES, V. M.; SANTOS, M. P.; FREITAS, S. M. L. Análise de açúcares e gorduras de recheios em biscoitos recheados sabor chocolate. Revista Ceres, Viçosa, v. 5, n. 1, p. 19-25, 2010.

GRIMALDI, R.; GONÇALVES, L. G.; ESTEVES, W. Características de gorduras comerciais brasileiras. Brazilian Journal of Food Technology, Campinas, v. 3, p. 159-164, 2000.

HARTMAN, L.; LAGO, R. C. A. Rapid preparation of fatty acid methyl esters from lipids. Laboratory Practice, London, v. 22, n. 6, p. 475-476, 1973. PMid:4727126.

HORWITZ, W. Official methods of analysis of the Association of Official Analytical Chemists. 18th ed. Maryland: AOAC, 2010. p. 20. Chapt. 41, Met. 996.06. (1 v.).

KALA, A. L. A. Studies on saturated and trans fatty acids composition of few commercial brands of biscuits sold in Indian market. Journal of Food Science and Technology, Mysore, v. 51, n. 11, p. 3520-3526, 2014. PMid:26396357. http://dx. doi. org/10.1007/s13197-014-1421-8.

KIM, S. S.; KIM, S. Y.; KIM, D. W.; SHIN, S. G.; CHANG, K. S. Moisture sorption characteristics of composite foods filled with chocolate. Journal of Food Science, Champaign, v. 64, n. 2, p. 300-302, 1999. http://dx.doi.org/10.1111/j.1365-2621.1999. tb15887.x.

LABUZA, T.; ROE, K.; PAYNE, C.; PANDA, F.; LABUZA, T. J.; LABUZA, P. S.; KRUSCH, L. Storage stability of dry food systems: influence of state changes during drying and storage. In:
INTERNATIONAL DRYING SYMPOSIUM, 14., 2004, São Paulo. Proceedings... Campinas: UNICAMP, 2004. p. 48-68. (v. A).

LEITE, J. T. C.; MURR, F. E. X.; PARK, K. J. Transições de fases em alimentos: influência no processamento e na armazenagem. Revista Brasileira de Produtos Agroindustriais, Campina Grande, v. 7, n. 1, p. 83-96, 2005. http://dx.doi.org/10.15871/15178595/rbpa.v7n1p83-96.

LINDEN, G.; LORIENT, D. Bioquímica agroindustrial: revalorización alimentaria de la producción agrícola. Zaragoza: Editorial Acribia, 1996. $426 \mathrm{p}$.

LIST, G. R. Decreasing trans and saturated fatty acid content in food oils. Food Technology, Chicago, v. 58, n. 1, p. 23-31, 2004.

MANLEY, D. Biscuit, cookie and cracker manufacturing manuals. Manual 1: ingredients. Cambridge: Woodhead Publishing Limited, 1998. 32 p.

MARTIN, C. A.; CARAPELLI, R.; VISANTAINER, J. V.; MATSUSHITA, M.; SOUZA, N. E. Trans fatty acids content of brazilian biscuits. Food Chemistry, London, v. 93, n. 3, p. 445-448, 2005. http:// dx.doi.org/10.1016/j.foodchem.2004.10.022.

MEILGAARD, M.; CIVILLE, G. V.; CARR, B. T. Sensory evaluation techniques. 4th ed. Boca Raton: CRC Press, 2006. 448 p.

ORMENESE, R. C.; MARCHESE, D. A.; LAGE, M. E.; MAMEDE, M. E. O.; ABREU, G. M. N.; COELHO, H. D.; MOURA, J. M. L. N.; NISHI, L. E.; CARRILHO, N. A.; GONZÁLEZ, N. B.; SILVA, M. A. A. P. Perfil sensorial e teste de consumidor de biscoito recheado sabor chocolate. Boletim do CEPPA, Curitiba, v. 19, n. 2, p. 277-300, 2001

PALM OIL LINK. WHO confirms health hazards of trans fatty acids. Malaysia: Dept. - POL, MPOPC, 2003. (Special issue, v. 13, n. 2-6).

QUEIROZ, M. B. Estudo da microestruturação de soluções supersaturadas multicomponentes utilizando fondant como sistema modelo. 2010. 144 f. Tese (Doutorado em Engenharia Química)-Faculdade de Engenharia Química, Universidade Estadual de Campinas, Campinas, 2010.

RIBEIRO, A. P. B.; MOURA, J. M. L. N.; GRIMALDI, R.; GONÇALVES, L. A. G. Interesterificação química: alternativa para obtenção de gorduras zero trans. Química Nova, São Paulo, v. 30, n. 5, p. 1295-1300, 2007. http://dx.doi.org/10.1590/ S0100-40422007000500043.

STAUFFER, C. E. Uso de las grasas y los aceites en productos de panaderia y confíteria. Grasas y Aceites, Sevilla, v. 3, n. 14, p. 420-432, 2006.

TROLLER, J. A. Influence of water activity on microorganisms in foods. Food Technology, Chicago, v. 34, p. 76-82, 1980.

UAUY, R.; ARO, A.; CLARKE, R.; L'ABBÉ, M. R.; MOZAFFARIAN, D.; SKEAFF, C. M.; STENDER, S.; TAVELLA, M. WHO scientific update on trans fatty acids: summary and conclusions. European Journal of Clinical Nutrition, London, v. 63, p. S68-S75, 2009. http://dx.doi.org/10.1038/ejcn.2009.15. 
Composição lipídica, características físicas e sensoriais de recheios de morango em biscoitos

Akamine, E. H. et al.

VARELA, P.; ARES, G. Novel techniques in sensory characterization and consumer profiling. Boca Raton: CRC Press, 2014. p. 144-149
ZENEBON, O.; PASCUET, N. S. Métodos físico-químicos para análise de alimentos. 4. ed. Brasília: Ministério da Saúde/ANVISA; São Paulo: Instituto Adolfo Lutz, 2005. cap. 4, met. 0,34B. 